\title{
How Service-Learning Promotes Intergenerational Harmony: A Case Study Of a Service-Learning Project in a Science Course
}

Sze Nga Cecilia Au Yeung, Lai Ki. Lam, and Jonathan J. Fong

\begin{abstract}
The Office of Service Learning and Science Unit at Lingnan University partnered with the Discovery and Education Department at Ocean Park (an aquatic theme park in Hong Kong) to develop a service learning project. Beyond service learning's traditional goals (enhanced student learning, useful service for a community partner), we examined the potential to develop intergenerational harmony. A service-learning project is a compulsory part of the science course CLD9008 Life Sciences: The Way Life Works, taught by Professor Jonathan Fong, Assistant Professor in the Lingnan University Science Unit. This course brings together traditional university students and elderly students from Lingnan University Elderly Academy Program directed by the Lingnan Institute of Further Education (LIFE). The elders are Hong Kong citizens aged 55 or above who voluntarily attend lectures and lessons with the students. In their service-learning project, they join intergenerational teams to transmit their new knowledge and educate Ocean Park visitors. The educational services (narration services at exhibits and assistance with interactive games) aim to fulfil Ocean Park's goal of enriching visitor experience, as well as promote awareness of marine conservation and sustainability. This study looks at on how including elders in a service-learning project facilitates open communication and reciprocal learning between age groups, and promotes intergenerational harmony. The authors wish to express their appreciation to Alan Wong and Orlando Chan from Ocean Park, Hong Kong for supporting this study.
\end{abstract}

Keywords: service learning, intergenerational harmony, open communication, reciprocal learning, science education

\section{Theoretical Framework and Literature Review}

Current scholarship affirms that service learning is an effective means to fostering reciprocal learning and communication between socially separated populations. Intergenerational harmony, in which multiple generations understand and support each other, thrives best by open communication and reciprocal learning between older and younger generations (Storm \& Storm, 2011; Dantzer et al., 2012). Intergenerational communication and reciprocal learning facilitate the transmission of traditional values and promote the sustainable development of the society (Kaplan et al., 1998; Wangyal, 2001). 
However, studies also identify obstacles emerging from both age groups. Students often have strong stereotypes about the elderly (Pecchioni et al., 2004) and the elderly frequently overestimate their willingness to talk with and learn from students (Beckert, 2007). These mindsets decrease communication and hinder reciprocal learning between older and younger generations (Storm \& Storm, 2011). Service learning allows students to render a service towards a particular social need and to reflect on their personal experience through journal writing and classroom discussion (Markus et al., 1993; Westacott \& Hegeman, 1996; Bringle \& Hatcher, 1996; Eyler, et al., 1997). Intergenerational service learning includes participants of different age groups. It connects elders and university students, and contributes to meaningful exchanges of knowledge and values (Santini et al., 2018; Hegeman et al., 2002; Nicolas, 2001; Knapp \& Stubblefield, 2000; Lowen, 1996). When elders and students interact during intergenerational service-learning projects, reciprocal learning allows all participants to be learners and teachers free of hierarchy (Hwang et al., 2014). The ultimate goal is for elders and university students to benefit educationally and socially, in the hope of changing students' stereotypes of elders and elders' unwillingness to learn from younger students (Gutheil et al., 2006; Duke et al., 2009; Lowe \& Medina, 2010).

To be successful, intergenerational Service learning should include organized, ongoing, and mutually rewarding interactions between older and younger generations (Newman \& Smith, 1997). Most intergenerational service-learning projects cast elders as service recipients and students as service providers, and focus only on student outcomes. Studies focusing on youth providing community service to the elderly far outnumber studies of aged adults as volunteers (June \& Andreoletti, 2018; Shea, 2017). In our study, we changed the approach to see how well elders and students work together as service providers. The outcomes and effects on both students and elders derived from two research questions:

(1) Were university students and the elderly more knowledgeable about each other after an intergenerational service-learning experience?

(2) Did the project benefit both university students and the elderly? If so, what had changed?

In this study, we examined whether an intergenerational service-learning project, with elders and students working together as service providers, promotes intergenerational harmony through reciprocal learning and open communication. We evaluated the impacts on both elderly and students through a questionnaire adopting a paradigm for intergenerational learning (Strom \& Strom, 2011). 


\section{Methods}

We researched this intergenerational service-learning project over two periods: the summer semester of 2018 and the regular semester of the 2018-2019 academic year. The services provided were narration of aquatic exhibits and interactive games for Ocean Park visitors. Participants formed intergenerational groups of one to two elderly and two to four university students. The summer semester had twelve participants (six students and six elders), while the regular semester had forty-five participants (thirty-five students and ten elders). As one of its graduation requirements, Lingnan University requires a service-learning project of at least thirty hours' duration. We divided this time between four major components. First, Ocean Park offered a 7-hour training session. In this training, participants learned about Ocean Park, the service

activity (narration service and interactive games), and customer service techniques. Second, each group conducted a total of twenty service hours at Ocean Park within an eight-week period dictated by the academic calendar. Third, a one-hour consultation session was conducted in the halfway through the period to discuss experiences and ways to improve. The last component was a 2-hour reflection session, which served as a wrap-up of the service project.

We used a mixed method for collecting data, combining quantitative and qualitative approaches. Quantitative data measured changes in participants' attitude. Qualitative data provided a deeper understanding of how attitude changed and in what way (Johnson \& Christensen, 2013). For the quantitative piece, we used pre- and post-test questionnaires to evaluate participant expectations before and after their service. The pre-test consisted of five questions on a five-point Likert scale and one open-ended question, while the post-test consisted of thirteen questions on a five-point Likert scale and one open-ended question. For the qualitative component, we used four ways to evaluate the effect of the service-learning project on elders and university students: observation of their on-site performance and group interaction, observation of midterm consultations, observation of the final reflection session, and study of the reflective essays detailing their experience.

\section{Results}

\section{Participant Characteristics and Data Collection Details}

The mean age of the elders was 63.4 years. Most (77\%) of them were retired. The mean age of the students was 20.4 years. Seventy-five percent of students had no previous service-learning experience and ninety-three percent did not live with their grandparents. Forty participants (66\% response rate) completed the pre-test questionnaire, while forty-five participants (75\% response rate) completed the post-test questionnaire. We collected forty-four reflective essays from elders and students. We edited the quotes used in this paper for clarity, while preserving the meaning. 
Participants' qualitative comments detailed participant expectations. Typical elder responses were: "To let me understand more about the students' thoughts, at the same time to share my own experience with them" and "Exchange different ideas between students and elders."

For university students, typical replies were to "Deal with each other peacefully," "I hope to communicate with the elders and other students to gain some more different kinds of insights and experience" and "Have fun and communicate with them [the elderly] comfortably".

Changes in Attitudes Following the Service-Learning Project

Responses to our questionnaires indicated that the project made a positive impact to both the university students and elders. It softened student stereotypes towards the elderly, strengthened intergenerational communication, increased participants' enthusiasm for reciprocal learning, and construction of a positive relationship between elders and students.

\section{Changed students' stereotypes towards elderly}

One of the questions on the pre- and post-test asked the participant their comfort level when speaking with the other age group (Table 1, Question 1). For the elderly, the mean score increased from 3.90 to 4.67 (maximum 5), while for university students, the mean score increased from 4.23 to 4.36 . In the reflective essay, many university students described their changing perceptions towards the elders. In this service-learning project, elders were not the service recipient, but rather they worked closely with the students as the service provider. Through this cooperation, many university students claimed they changed their stereotypes of the elderly. The following student excerpts illustrate these changes:

In the beginning, we thought that he (elderly team-mate) was not capable of doing many things since he was older than us. However, in truth, he is very smart and tough.

I thought there would be a generation gap so that we may not communicate well. But after the service learning I feel comfortable talking with the elderly. Her (elderly) heart and thoughts are similar to our so we had many common topics to discuss.

I initially thought that it would be difficult to get along with elderly people due to the generation gap. However, working with elderly people was one of the most wonderful and memorable experiences in the Service-Learning project. 
The Service-Learning project was worth doing because I have learned a lot and established a bond between members that I never expected. I never thought I could be friends with an elderly person because I thought we have very different lifestyles and different concepts, ideas.

For me, this is a valuable experience. It changed my view of elderly people and gave me a new understanding of them. The elders that I attend class with are active, talkative, and not be too shy to ask questions.

\section{Strengthened intergenerational communication}

One question in the pre- and post-test focused on to what extent the participant gained understanding for the values that guide the behavior of the other age group (Table 1, Question 2). The mean score of both elders and students increased when comparing before and after the service. For elders, the mean score increased from 3.9 to 4.44, while for students, the mean score increased from 3.72 to 3.81 . Another question focusing on knowing how the other generation interprets events, the mean score of elders increased from 3.72 to 4.11, while for university students, the mean score increased from 3.71 to 4.29 (Table 1, Question 3). Most participants agreed that the arrangement of students paired with elderly improved their interaction with the other generation. The average score was 4.33 for elderly and 4.46 for students (Table 2, Question 2).

On-site observations found that the university students and the elders communicated frequently to complete their tasks. Two examples stand out in the elders' reports and the university students' reflective journals. For the interactive booth game, the teams discussed division of labor, such as who will manage the queue and who is responsible for playing games and interacting with visitors. Similarly, as Ocean Park visitors speak a variety of languages (primarily Cantonese, Mandarin, and English), teams assigned the appropriate teammate to interact with a visitor, depending on language proficiency. If any university students were not strong in Cantonese (e.g. non-Chinese Hong Kong citizens or mainland Chinese students), they would ask elders for help. The following excerpts from the reflective journals illustrate these findings:

She (elderly) always shares her own life experience with us and talked about something related to her volunteer works in her daily life.

Our elder member gave us a lot of support and shared his own experiences with us. In particular, he would share his opinions on working as a team and lead us methodically.

She (elderly) gave a lot of advice to us during the service. For example, she taught us 
how to approach tourists in a better way during our narration service. She put a lot of effort in engaging the visitors.

At lunchtime, we exchanged a lot of knowledge. He (an elderly man) told me about his career, and he gave me a lot of advice on my future work. I shared with him the current situation of my university life and about the academic system.

Service at Ocean Park provides a very good opportunity for students and elderly to communicate because we stay together for the whole day. We had lunch and took breaks together, sharing past stories as well as talking about the future. I (elderly) gave them some suggestions and we discussed those suggestions.

\section{Increased enthusiasm for reciprocal learning}

Three pre- and post-test questions relate to reciprocal learning. Mean scores of both elders and university students increased when asked about gaining insight about young/old world (Table 1, Question 5). For elders, the mean score increased from 3.81 to 4.44, while for the students, it increased from 3.57 to 4.25 . They also scored higher on whether mixed age groups encouraged them to learn from the other (Table 2, Question 1). The mean score was 4.44 for elders, and 4.40 for university students. On whether they received support from each other during the service, both university students (mean score $=4.78$ ) and elders (mean score $=4.43$ ) scored relatively high (Table 2, Question 6). In their reflective journals, nearly all students and elders agreed that different age groups had different strengths. Students related better to younger visitors, being more familiar with current issues, while elders are able to calmly handle unexpected issues.

The following extracted statements illustrate the above findings:

We talked to him (elderly teammate) about the relationship between two different generations, particularly parents and children. Listening to the perspectives of different generations, we learned a lot about what we did not see from our perspective.

After working with elderly people for several weeks, I thought that they created a positive learning environment because they were more eager to learn when compared to the students. They showed a good attitude to lifelong learning [the ongoing and selfmotivated pursuit of knowledge]. This attitude is very important for us students because we sometimes forget why we are studying.

They (elders) have much more life experience than undergraduates, and they also have a passion to study. When I talked with the elderly, I thought, I want to be like them when I am old. I learned a lot from the discussion and their attitude. 
He (elder) diligently studied the materials used for the narration. When we forgot any information about sea animals, we could immediately ask him.

\section{Constructing a positive relationship between elders and university students}

In the post-test, both university students and elders strongly agreed that the arrangement of students paired with elderly fostered a positive relationship between generations. The mean score for elders was 4.67, while the mean score for students was 4.50 (Table 2, Question 3). For the post-test question on whether a cooperative service-learning project can promote intergenerational harmony, the mean scores were 4.55 (elders) and 4.36 (students) (Table 2, Question 7). The content of their reflective journals echoed the survey results:

If there is another chance for me to work with elders again, I am willing to do so.

We (students) were lucky we could cooperate with the elders during the service. In my opinion, having the elderly around is good.

Learning together with different generations was a wonderful experience because it helped to build respect and positive engagement.

This part (intergenerational cooperation) is my favorite part. I am so thankful that we had the opportunity to learn and work with elders. The generation gap almost did not exist between us, thanks to everyone's cooperation. We acted like a family. We took care of them and they took care of us.

I like such teamwork with both elder and the students.

To me, I had a nice experience in a harmonious relationship with my teammates. 
Table 1. Average pre-test and post-test scores among elders and university students

\begin{tabular}{|l|l|l|l|l|}
\hline \multirow{2}{*}{ Question } & \multicolumn{2}{l|}{ Elders } & \multicolumn{2}{l|}{ University Students } \\
\cline { 2 - 5 } & Pre-test & Post-test & Pre-test & Post-test \\
\hline $\begin{array}{l}\text { I felt comfortable when } \\
\text { speaking to them }\end{array}$ & 3.9 & 4.67 & 4.23 & 4.36 \\
\hline $\begin{array}{l}\text { I valued their guidance and } \\
\text { understood their behavior. }\end{array}$ & 3.9 & 4.44 & 3.72 & 3.81 \\
\hline $\begin{array}{l}\text { I got to know how other } \\
\text { generations interpret events }\end{array}$ & 3.72 & 4.11 & 3.71 & 4.29 \\
\hline $\begin{array}{l}\text { I recognize students or } \\
\text { elders' vision of the future }\end{array}$ & 3.81 & 4.11 & 3.71 & 4.14 \\
\hline $\begin{array}{l}\text { I gained insight about the } \\
\text { young/old world }\end{array}$ & 3.81 & 4.44 & 3.57 & 4.25 \\
\hline
\end{tabular}

Table 2. Average score of elders and university students from the post-test

\begin{tabular}{|l|l|l|}
\hline Question & Elders & University Students \\
\hline $\begin{array}{l}\text { 1) The arrangement of students paired with elderly encourage } \\
\text { me to learn from students/elders }\end{array}$ & 4.44 & 4.40 \\
\hline $\begin{array}{l}\text { The arrangement of students paired with elderly increase the } \\
\text { interaction with students/elders }\end{array}$ & & \\
\hline $\begin{array}{l}\text { 3) The arrangement of students paired with elderly build } \\
\text { positive relationship between you and students/elders }\end{array}$ & 4.67 & 4.50 \\
\hline 4) I think my relationship with students/elders is closer & 4.44 & 4.46 \\
\hline 5) I am happy to work with students/elders as a group & 4.78 & 4.61 \\
\hline 6) I gained support from students/elders during the service. & 4.78 & 4.43 \\
\hline $\begin{array}{l}\text { 7) To what extend do you agree that the service-learning } \\
\text { project can promote intergenerational harmony? }\end{array}$ & 4.55 & 4.36 \\
\hline
\end{tabular}

\section{Discussion}

In this study, we take a different approach to intergenerational Service learning. Instead of having students be the service provider and elders being the service recipient, we make students and elders work together to be the service provider. This approach has a positive impact on both elders and students, in terms of open communication and reciprocal learning, in turn promoting intergenerational harmony. We discuss our findings in further detail below. 


\section{Different goals and expectations influence participant perception}

The responses on the pre-test showed that the elders and the university students different expectations towards the service-learning project. Elders were generally willing to work with students, while students were worried about cooperating with elders. This is probably due to the course arrangement. The elders joined the course knowing the service-learning project's details in advance. They understood that they had to cooperate with the students in the Ocean Park service-learning project. It was obvious that those elders not interested in working with university students would not apply or withdraw from the course. Therefore, to a certain extent, these elder participants were a self-selecting group who looked forward to cooperating with the students. On the other hand, the students did not know the details of the service-learning project in advance. Many students registered for the course to meet two Lingnan University graduation requirements for one science-related course and one service-learning course. As in other studies, student participants may have felt obliged to join the service-learning project (Stukas et al, 1999), or perhaps joined the course to 'simply fulfil a course requirement, gaining little out of the experience beyond a grade' (Knecht \& Martinez, 2012). Based on the result of the post-test, students experienced a positive change in their view of the elderly. We believe the project's structure facilitated this change: both of the elders and the students played the same role of being a service provider. Both groups of participants carried the same responsibilities and expectations from Ocean Park, regardless of age. We found that effective communication and utilization of talent between the elders and the students were key elements to make this intergenerational Service-Learning project successful.

\section{Intergenerational Service-Learning Projects Promote Reciprocal Learning and Open Communication}

In the reflective journals, the university students and the elders provided details on the way the teams encountered problems and how they resolved them. For example, two commonly reported problem were the division of labor among teammates and strategies on attracting visitors to participate in interactive games. To solve these problems, teams had to openly discuss, share opinions, and mutually agree on a solution. As all participants, both students and elders, were working at Ocean Park for the first time, no one was an expert, and thus no assumed their opinion was best. In such a situation, we believe both students and elders were encouraged to openly communicate and respect the opinions of other team members.

In one particular case, the university students relied on their elder teammates: an argument began two groups of visitors over the proper queueing procedure. The university students involved felt anxious and helpless at that moment, but the elder teammates used their maturity to resolve the situation calmly. We believe such situations stimulated the students' open-mindedness and respect towards elders. In such a case, the elder acts as a role model for which students are able 
to learn from and follow. How the elder participants calmly deal with contingencies served a framework for the students to refer to when having a need to solve similar problems in the future.

In addition to fuller life experiences of the elderly, students also learned from observing the attitude of the elderly towards the service-learning project. Elders took the responsibility of the narration service very seriously, diligently studying the materials before going to Ocean Park. Many university students mentioned that the elders were more familiar with the information than they were. The effort of the elders pushed the students to stay engaged and work harder. We believe the elders performed so well principally for two reasons: time and sense of responsibility. Elders were able to devote more time to the project because most of them were retired, while the students had to manage four or five academic courses per semester. Furthermore, the elderly had a greater sense of responsibility towards this service-learning project. Our impression was that the elderly viewed this project like a job, and believe it was their responsibility to be well prepared and perform well. This may be because of the richer life experiences of elders, or because the course was voluntary for the elders, but compulsory for students. Regardless of the differences, the students were able to learn by observing the elders. Similar to the existing studies on intergenerational service learning, the student participants regard the elders as role models to follow (Fair \& Daphane, 2014; Aemmi \& Moonaghi, 2017).

\section{Mutual learning through personal stories}

One service day at Ocean Park lasted for 7 hours. Throughout the day, teams took breaks for rest (thirty minutes, twice daily) and lunch (one hour, once daily). Teams often stayed together during breaks, providing opportunities for them to chat in-depth about larger topics. We believe this facilitated mutual learning. Two common topics amongst the teams were about the 'future' and 'current trends'. In these discussions about the 'future', the university students would share their dreams and visions, while the elderly would provide advice based on their life experiences. The elderly wanted to understand 'current trends' to better understand their own children or grandchildren. Some elderly participants noted that this kind of discussion during service was much more in-depth than the in-class discussions. This is likely because the in-class discussions focused assigned topics focusing on the lecture material, and these discussions would not continue after class.

On the other hand, both the elders and the students mentioned the environment at Ocean Park was relaxed, and teams were free to discuss any topic. Such discussions about common interests and life experiences provided a deeper understanding of teammates and improved mutual learning. 


\section{Limitations}

We note three main limitations to our study. First, elderly participants were a self-selected group. Elders registered for the course knowing it was an intergenerational service-learning project, and were willing to cooperate with the university students. They fully intended to engage actively, and therefore tended to have positive expectations. Such a scenario may create self-selection bias, influencing the result (Thomson, 2003). Second, data from the summer-semester group arrived relatively late (around 6 months after service was completed) due to logistical problems. Those participants, relying on memory to complete the questionnaire, may not have been able to provide as many, or as accurate, details of their experiences. Lastly, the response rate of the elderly participants was relatively low. We conducted the questionnaire online, which we believe affected elderly participation. Some elderly were perhaps not familiar or comfortable with the online questionnaire, and decided not to respond.

\section{Conclusions and Contributions to Theory and Practice}

This study provides strong evidence on the positive impact of intergenerational servicelearning projects upon open communication and reciprocal learning, leading to greater intergenerational harmony (Storm \& Storm, 2011; Dantzer et al, 2012). Many previous studies on intergenerational harmony place elders as the service recipients/beneficiaries, while students are service providers. At Ocean Park, elders and students are service providers, working together as a team to provide service to the public. All participants are equal, and neither the elders nor the university students enjoy special privileges. Older and younger participants are encouraged to be open-minded and to cooperate closely with each other.

Our findings are coherent with Chan et al. (2013): "Through learning, investigating, communicating and solving problems together, students and elders cooperate and complete the learning journey hand in hand." Through engaging in a project with a common goal, students and elders experienced a deeper understanding of each other. To form a successful team, members had to establish a strong bond, communicate well, and be committed to the same goal. Participants discovered that each team member had particular strengths and weaknesses, and that cooperation created a team where the whole is greater than the sum of its parts. The Ocean Park service-learning project created an environment where participants were willing to learn from each other, regardless of age. Our conclusion supports the existing literature's findings (e.g. Storm \& Storm, 2011; Dantzer et al, 2012) that when elders and students work together in a service-learning project, their trust and communication strengthens and promotes the sustainable development of society. 


\section{Acknowledgement}

The authors would like to express their appreciation to Alan Wong and Orlando Chan from Ocean Park, Hong Kong for supporting this study.

The work described in this paper is supported by a grant from the Cross-institutional Capacity Building for Service-Learning in Hong Kong Higher Education Institutions funded by the University Grants Committee of the Hong Kong Special Administrative Region, China (Project No. PolyU4/T\&L/16-19). 


\section{References}

Aemmi, S. Z., \& Karimi Moonaghi, H. (2017). Intergenerational Learning Program: A Bridge between Generations. International Journal of Pediatrics, 5(12), 6731-6739. doi:

10.22038/ijp.2017.28072.2430

Beckert, T., Strom, R., Strom, P., Yang, C., \& Singh, A. (2007). Parent Success Indicator: Crosscultural development and factorial validation. Educational and Psychological Measurement, 67(2), 311-327. https://doi.org/10.1177/0013164406292039

Bringle, R. G., \& Hatcher, J. A. (1996). Implementing service learning in higher education. The Journal of Higher Education, 67(2), 221-239. https://doi.org/10.1080/00221546.1996.11780257

Chan, C. M., Ma, H. K., Wong, L. K., Chan, K. M., Leung, W. Y., Tang, H. H., \& Ho, M. C. (2013). A handbook for using elder academy as a platform of other learning experiences. Hong Kong: Lignan University. Retrieved from https://commons.ln.edu.hk/osl_book/1/

Dantzer, F., Keogh, H., Sloan, F., \& Zekely, R. (2012). Learning for active ageing \& intergenerational learning (Report). Taastrup, Denmark: European Network for Intergenerational Learning. Retrieved from https://publications.europa.eu/en/publication-detail//publication/c9f75907-13b8-488c-b60e-c84690666f17

Dorfman L.T., Murty S.A., Ingram J.G., Evans R.J., \& Power J.R. (2004). Intergenerational service learning in five cohorts of students: Is attitude change robust? Educational Gerontology, 30(1), 39-55. https://doi.org/10.1080/03601270490248446

Eyler, J., Giles, D. E., \& Braxton, J. (1997). The impact of service learning on college students. Michigan Journal of Community Service Learning, 4, 5-15. Retrieved from http:/hdl.handle.net/2027/spo.3239521.0004.101

Fair, C. D., \& Delaplane, E. (2015). "It is good to spend time with older adults. You can teach them, they can teach you": Second grade students reflect on intergenerational service learning. Early Childhood Education Journal, 43(1), 19-26. https://doi.org/10.1007/s10643-014-0634-9

Gutheil, I.A., Chernesky, R.H., Sherratt, M.L., 2006. Influencing student attitudes toward older adults: results of a service learning collaboration. Educational Gerontology, 32(9), 771-784. https://doi.org/10.1080/03601270600835470

Johnson, R. B., Christensen, L. B. (2013). Educational research: Quantitative, qualitative, and mixed approaches (5th ed.). Thousand Oaks, CA: Sage. 
June, A., \& Andreoletti, C. (2018). Participation in intergenerational service-learning benefits older adults: A brief report. Gerontology \& Geriatrics Education, 2018, 1-6.

https://doi.org/10.1080/02701960.2018.1457529

Kaplan, M., Kusano, A., Tsuji, I., \& Hisamichi, S. (1998). Intergenerational programs:

Support for children, youth and elders in Japan. Albany, NY: New York State University Press.

Knapp, J. L., \& Stubblefield, J. D. P. (2000). Changing students' perceptions of aging: the impact of an intergenerational service-learning course. Educational Gerontology, 26, 611621. https://doi.org/10.1080/03601270050200617

Knecht, T., \& Martinez, L. M. (2012). Engaging the reluctant? Service learning, interpersonal contact, and attitudes toward homeless individuals. PS: Political Science \& Politics, 45(1), 106-111. https://doi.org/10.1017/s104909651100179x

Loewen, J. (1996). Intergenerational learning: What if schools were places where adults and children learned together? Educational Research Information Services (ERIC, ED 404014). Retrieved from https://files.eric.ed.gov/fulltext/ED404014.pdf

Lowe L.A. \& Medina V.L. (2010) Service-learning collaborations: A formula for reciprocity. Families in Society, 91(2), 127-134. https://doi.org/10.1606/1044-3894.3970

Markus, G. B., Howard, J. P. F., \& King, D. C. (1993, Winter). Integrating community service and classroom instruction enhances learning: Results from an experiment. Educational Evaluation and Policy Analysis, 15(4), 410-419.

Nichols, A. H. (2001). Designing intergenerational service-learning courses based on student characteristics. Educational Gerontology, 27, 37-48.

https://doi.org/10.1080/036012701750069030

Pecchioni, L.L., Ota, H., Sparks, L. (2004). Cultural Issues in Communication and Aging, 2nd Ed. Hillsdale, NJ: Lawrence Erlbaum Associates.

Santini, S., Tombolesi, V., Baschiera, B., \& Lamura, G. (2018). Intergenerational programs involving adolescents, institutionalized elderly, and older volunteers: Results from a pilot research-action in Italy. BioMed Research International, 2018.

https://doi.org/10.1155/2018/4360305 
Shea, J. (2017). Senior volunteering in service to community elders in Shanghai: Bringing together agendas for productive aging and community-based social support for the aged in China. Ageing International, 42(2), 205-235. https://doi.org/10.1007/s12126-016-9270-6

Strom, R., \& Strom, P. (2011). A paradigm for intergenerational learning. In M. London (Ed.), Oxford handbook of lifelong learning (pp. 133-146). New York, NY: Oxford University Press.

Stukas, A., Snyder, M., \& Clary, E.G. (1999). The effects of mandatory volunteerism on intentions to volunteer. Psychological Science, 10(1), 59-64. https://doi.org/10.1111/14679280.00107

Thompson, L. F., Surface, E. A., Martin, D. L., \& Sanders, M. G. (2003). From paper to pixels: moving personnel surveys to the web. Personnel Psychology, 56(1), 197-227. https://doi.org/10.1111/j.1744-6570.2003.tb00149.x

Wangyal. T. (2001Summer). Enduring social sustainability: Can Bhutan's educational system ensure intergenerational transmission of values? Journal of Bhutan Studies, 3(1), 106-131. Retrieved from https://www.bhutanstudies.org.bt/category/journal-of-bhutan-studies/

Westacott, B. M., \& Hegeman, C. R. (1996). Service learning in elder care: A resource manual. Albany, NY: The Foundation for Long Term Care. 


\section{Author Information}

Sze Nga Cecilia Au Yeung

Department of Marketing and International Business, Lingnan University,

Hong Kong

ceciliaauyeung@ln.hk

Lai Ki Lam

Office of Service-Learning, Lingnan University,

Hong Kong

joylam@ln.edu.hk

Jonathan J. Fong

Science unit, Lingnan University,

Hong Kong

jonfong@ln.edu.hk 